Original Paper http://ajol.info/index.php/ijbcs http://indexmedicus.afro.who.int

\title{
Phytochemical screening of Saye, a traditional herbal remedy for malaria
}

\author{
O. DA ${ }^{1,6^{*}}$, M. TRAORÉ COULIBALY ${ }^{1}$, J.C.W. OUEDRAOGO ${ }^{2}$, B. YARO ${ }^{2}$, \\ R.S. YERBANGA ${ }^{1}$, F. KINI ${ }^{2}$, B. KOAMA ${ }^{1}$, Z.P. DAKUYO ${ }^{4}$, J.B NIKIEMA ${ }^{3}$, \\ G.A. OUÉDRAOGO ${ }^{6}$, M.G. MATSABISA ${ }^{5}$ and J.B. OUÉDRAOGO ${ }^{1}$ \\ ${ }^{I}$ Direction Régionale de l'Institut de Recherche en Sciences de la Santé (IRSS-DRO/CNRST), \\ BP 545 Bobo-Dioulasso, Burkina Faso. \\ ${ }^{2}$ Institut de Recherche en Sciences de la Santé (IRSS), 03 BP 7192 Ouagadougou, Burkina Faso. \\ ${ }^{3}$ Direction Générale de la Pharmacie, du Médicament et des Laboratoires (DGPML), \\ 03 BP 7009 Ouagadougou 03, Burkina Faso. \\ ${ }^{4}$ Pharmacie de la Comoé, Phytofla, BP 293 Banfora, Burkina Faso. \\ ${ }^{5}$ Indigenous Knowledge System Unit of the Medical Research Council (IKS/MRC), Cape Town, South Africa, \\ PO Box / Posbus 339, Bloemfontein 9300, Republic of South Africa / Republiek van Suid-Afrika \\ ${ }^{6}$ Université Polytechnique de Bobo-Dioulasso, Laboratoire de Recherche en Science de la Santé et \\ Biotechnologie Animale (LARESBA), BP 1091 Bobo-Dioulasso, Burkina Faso. \\ "Corresponding author; E-mail: olobouff@yahoo.fr ;Tel.: +226 70742977
}

\section{ACKNOWLEDGMENTS}

We acknowledge the financial support from UMOEA PACER-2 programme (Programme d'appui et de développement des Centres d'excellence régionaux).

\begin{abstract}
A phytochemical assay was conducted to establish the chemical profile of "Saye", a mixture of leaf of Cassia alata, root of Cochlospermum planchonii and whole plant of Phyllantus amarus, used as antimarial remedy. Water and organic extracts were prepared. Characterization of phytoconstituents using specific chemical reagents was performed in tubes, by thin layer chromatography and by high performance liquid chromatography. Steroids and/or triterpenes, cathechic tannins were identified in the decocted and the macerated water extracts of "Saye". An anthraquinone with a retention time Rt corresponding to 3.34 min was identified by the HPLC analysis.
\end{abstract}

(c) 2015 International Formulae Group. All rights reserved.

Keywords: Chemical profile, anthraquinones, steroids, triterpenes, tannins.

\section{INTRODUCTION}

The African Region continues to shoulder the heaviest malaria burden with 214 million new cases of malaria and 438000 deaths (World malaria report, 2015). With the resistance of Anopheles mosquito to 
insecticides and Plasmodium species to most of the drugs currently in use (White, 2004), there is a call for a return to natural products as antimalarial drugs or as sources of inspiration for the development of novel drugs (Ginsburg et al., 2011). In Burkina Faso, a traditional preparation named "Saye", manufactured by mixing dried rhizomes of Cochospermum planchonii, leaves of Cassia alata and whole plant of Phyllanthus amarus is used for the treatment of uncomplicated malaria (Dakuyo et al., 2015). Extracts from each individual plant contained in Saye or their $2 \times 2$ mixture were found to inhibit malaria parasites (Da et al., 2014). In the framework of a clinical study, there was a need of chemical standardisation of "Saye". The objective of the study was to establish the chemical profile of "Saye" and its content plants.

\section{MATERIALS AND METHODS Plant materials}

The leaf powder of Cassia alata, the root powder of Cochlospermum planchonii, the whole plant powder of Phyllantus amarus and "Saye", were all supplied by Phytofla laboratory, with market authorization number: 0497920050N110000/2011.

\section{Extracts preparation}

Crude extracts from individual plant powder (15 g) and "Saye" (15 g) were prepared by maceration during $24 \mathrm{~h}$ successively with chloroform (150 mL), methanol $(150 \mathrm{~mL})$ and distilled water $(150$ $\mathrm{mL})$. Organic extracts obtained were dried with an evaporator Buchi R110 type MKE 6540/2. Water extracts from individual plant powder (50 g) and "Saye" (50 g) was also prepared by maceration $(24 \mathrm{~h})$ or decoction (10 min) with water $(1 \mathrm{~L})$. After filtration, all water extracts were frozen at $-20{ }^{\circ} \mathrm{C}$ and freeze-dried using a FTS Systems Dura-Dry MPII®, Floor model freeze dryer. Aliquots (1 $\mathrm{g}$ ) of these extracts were re-dissolved in 30 $\mathrm{mL}$ of distilled water, acid hydrolyzed under reflux for $30 \mathrm{~min}$ and then extracted (liquidliquid extraction) with chloroform.

\section{Phytochemical analysis of the extracts by qualitative methods}

The detection of phytoconstituents such as alkaloids, flavonoids, steroids, tannins and saponins in the extracts was performed in tubes according to Ciulei (1982) method.

Phytochemical analysis of the fractions by thin layer chromatography (TLC)

TLC was carried out on a 60 F254 silica gel plate in glass, Merck $(20 \mathrm{~cm}$ x 10 $\mathrm{cm})$. Hydrolyzed and non-hydrolysed extracts were spotted on the plate and developed in 2 different eluent systems: (a) chloroform/acetone (20:10), (b) ethyl acetate/formic acid/acetic acid/water (50:5.5:5.5:13). The various spots were visualized by exposure of the plates to Neu, Keddee, Anisaldehyde sulfuric acid, ferric chloride $\left(\mathrm{FeCl}_{3}\right), \quad$ Liebermann-Burchard, Dragendor'ff and ammonia aqueous solution $25 \%$ reagents. A TLC monitoring of the chloroform extract by liquid-liquid extraction was done and the main compounds purified by high performance liquid chromatography (HPLC).

\section{RESULTS}

Phytochemical profile of the extracts by the qualitative method

Over all, "Saye" extracts were found to contain esters, glycosides, steroids and /or triterpens, flavonoids, carbohydrates, gallic tannins, carotenoids, saponins, flavonic aglycones, anthocyanosides, cardenolides, anthraquinones and reducing compounds. Emodols were more available in Cassia alata leave extracts. Flavone aglycones were present in Cochlospermum planchonii. Glycosides and anthocyanosides were present in the hydrolyzed phase of the methanolic and aqueous fractions of each plant. Flavonosides as well as cardenolides were present in Cochlospermum planchonii. Anthracenosides were more available in Cassia alata leaves. 
Gallic tannins, saponins, reducing compounds and carbohydrates were present in the nonhydrolyzed methanolic fraction and in each plant aqueous extract (Table 1).

Phytochemical profile of the extracts by TLC analysis

Steroids and/or triterpenes, cathechic tannins and anthraquinones were identified in the decocted and the macerated water extracts of "Saye". The DCM/MeOH extract of "Saye" has also shown the presence of steroids and/or triterpenes. Steroids and/or triterpenes were found in the decocted and macerated extracts of each plant whereas anthraquinones and cathechic tannins were only found in Cassia alata leaves and the whole plant of Phyllanthus amarus (Table 2).

\section{Identification of the chemical markers from TLC profiling of the fractions}

Three main spots with different Rfs were identified from TLC analysis, one from each plant: $\mathrm{Rf}=0.59$, (Cochlospermum Planchonii), $\mathrm{Rf}=0.75$ (Cassia alata) and $\mathrm{Rf}$ $=0.90$ (Phyllanthus amarus). The compound from Cassia alata purified by HPLC was identified as an anthraquinone with a retention time $t_{R}=3.34 \min$ (Figure 1$)$. The spots $(\mathrm{Rf}=$ 0.59 and $\mathrm{Rf}=0.90$ ) have the characteristics of steroids and triterpenic compounds.

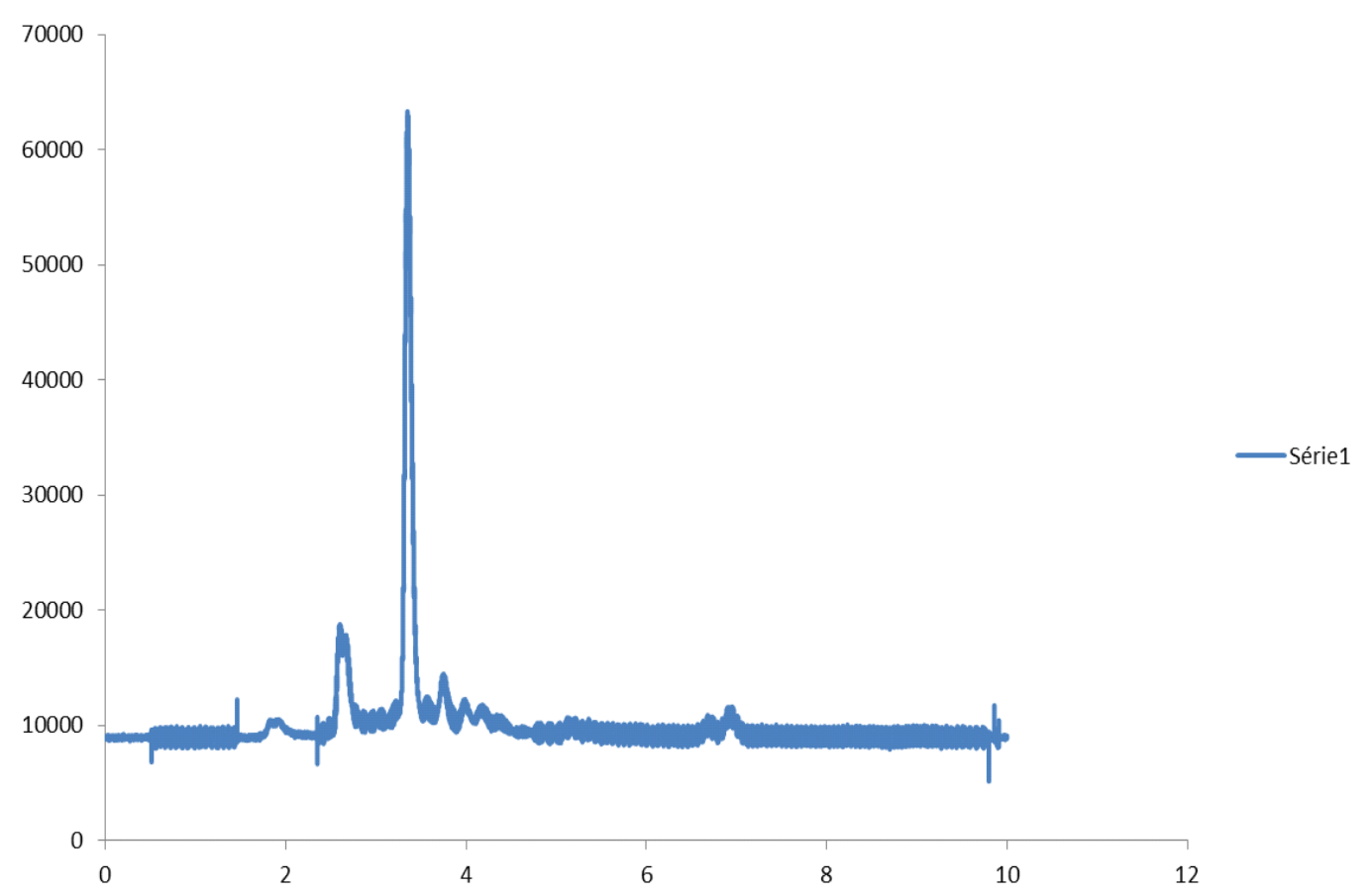

Figure 1: HPLC chromatogram of chloroform extract. Mobile phase in isocratic mode: acetonitrile$0.1 \%(\mathrm{v} / \mathrm{v})$ formic acid in water (3:2); Flow rate: $1 \mathrm{~mL} / \mathrm{min}$; detection wavelength: $\lambda=250 \mathrm{~nm}$. 
O. DA et al. / Int. J. Biol. Chem. Sci. 9(6): 2940-2946, 2015

Table 1: Compounds identified in the extracts by qualitative phytochemical screening.

\begin{tabular}{|c|c|c|c|c|}
\hline Compounds & $\begin{array}{c}\text { Tisane Saye } \\
\text { (Decocted extract) }\end{array}$ & Phyllantus amarus & Cassia alata & Cochlospermum planchonii \\
\hline \multicolumn{5}{|l|}{ Chloroformic extract } \\
\hline Steroids and/or triterpenoids & ++ & ++ & ++ & ++ \\
\hline Flavone Aglycones & ND & ND & ND & + \\
\hline Emodols (Anthracenoside and Anthracenoside Aglycone) & ++ & ND & ++ & ND \\
\hline Alkaloids & ND & ND & ND & \\
\hline Coumarines and /or coumarin derivatives & ND & ND & ND & ND \\
\hline Carotenoids & + & + & + & ++ \\
\hline \multicolumn{5}{|l|}{ Hydrolyzed aqueous and methanolic Fraction } \\
\hline Glycosides & ++ & ++ & ++ & ++ \\
\hline Flavonosides & ND & ND & ND & + \\
\hline Anthracenosides & ++ & ND & ++ & ND \\
\hline Coumarines derivatives & ND & ND & ND & ND \\
\hline Cardenolides & ND & ND & ND & + \\
\hline Anthocyanosides & + & ++ & ++ & + \\
\hline \multicolumn{5}{|l|}{ Non-hydrolyzed aqueous and methanolic fraction } \\
\hline Tannins & ++ & ++ & + & ++ \\
\hline Saponins & ++ & + & + & ++ \\
\hline Alkaloids & ND & ND & ND & ND \\
\hline Reducing compound & ++ & ++ & ++ & + \\
\hline Carbohydrates (Oses) & + & + & + & ++ \\
\hline Carbohydrate (polyoses) & ++ & ND & ND & ++ \\
\hline
\end{tabular}


O. DA et al. / Int. J. Biol. Chem. Sci. 9(6): 2940-2946, 2015

Table 2: Chemical profile of Saye established by thin layer chromatography analysis.

\begin{tabular}{|c|c|c|c|c|c|c|c|c|c|c|c|c|}
\hline \multirow[t]{2}{*}{ Compounds } & \multicolumn{3}{|c|}{ Cassia alata } & \multicolumn{3}{|c|}{$\begin{array}{c}\text { Phyllanthus } \\
\text { Amarus }\end{array}$} & \multicolumn{3}{|c|}{$\begin{array}{c}\text { Cochlospermum } \\
\text { planchonii }\end{array}$} & \multicolumn{3}{|c|}{ Tisane saye } \\
\hline & DCM/MeOH & $\mathbf{M}$ & d & DCM/MeOH & $\mathbf{M}$ & D & DCM/MeOH & $\mathbf{m}$ & d & DCM/MeOH & $\mathbf{m}$ & d \\
\hline Alkaloid & nd & $\mathrm{Nd}$ & nd & nd & $\mathrm{Nd}$ & $\mathrm{Nd}$ & nd & nd & nd & nd & nd & nd \\
\hline Flavonoid & nd & $\mathrm{Nd}$ & nd & nd & $\mathrm{Nd}$ & $\mathrm{Nd}$ & nd & nd & nd & nd & nd & nd \\
\hline $\begin{array}{l}\text { Steroid and/or } \\
\text { triterpene }\end{array}$ & ++ & + & + & ++ & + & + & + & + & + & ++ & + & + \\
\hline Tanin & + & $\mathrm{Nd}$ & + & + & ++ & ++ & + & nd & nd & + & + & + \\
\hline Anthraquinone & + & ++ & + & nd & $\mathrm{Nd}$ & $\mathrm{Nd}$ & nd & nd & nd & nd & ++ & ++ \\
\hline Cardenolide & nd & $\mathrm{Nd}$ & nd & nd & $\mathrm{Nd}$ & $\mathrm{Nd}$ & nd & nd & nd & nd & nd & nd \\
\hline
\end{tabular}




\section{DISCUSSION}

The main chemical groups found in "Saye" are tannins, anthraquinones, steroids and/or triterpenes. These chemical compounds, which were also found in the extracts of the individual plant, may be supportive of the antiplasmodial activity of the extracts (Da et al., 2014). In most studies, flavonoids were reported in the three plants: Phyllanthus amarus (Hemant et al., 2013); Cochlospermum planchonii (Nafiu et al., 2011); Cassia alata (Matthew et al., 2013). Previous works have also revealed the presence of tannins in the whole plant of Phyllanthus amarus (Obianime et al., 2009), Cochlospermum planchonii (Ezeja et al., 2010) and in the leaves of Cassia alata (Awomukwu et al., 2015). As in previous studies (Matthew et al., 2013) anthraquinones were found in abundance in the leave extracts of Cassia alata and in "Saye". Triterpenes were found in Phyllanthus amarus (Hemant et al., 2013), Cochospermum planchonii (Nafiu et al., 2011) and Cassia alata (Kayembe et al., 2012). Steroids were present in Phyllanthus amarus (Hemant et al., 2013), Cochospermum planchonii (Nafiu et al., 2011) and Cassia alata (Matthew et al., 2013). Cochloxanthine and dihydrocochloxanthine were previously identified in Cochlospermum species and found to have an antimalarial activity with an $\mathrm{IC}_{50}$ estimated to $1 \mu \mathrm{g} / \mathrm{ml}$ (Benoit-Vical et al., 2001).

\section{Conclusion}

This study showed that the main chemical components in "Saye" are tannins, anthraquinones, steroids and/or triterpenes. The results allowed establishing in part the chemical profile of "Saye" that will be used for to its quality control during the clinical study. Taking into account all the results from prior works, Cochloxanthine and dihydrocochloxanthine anthraquinones, flavonoids and kaempferol might be the target chemical compounds for the choice of the chemical marker of "Saye".

\section{COMPETING INTERESTS}

The other authors declare that they have no competing interests.

\section{AUTHORS' CONTRIBUTIONS}

The study was conceived by MTC, JBO, JBN, JCWO, FK and MGM. It was run by IRSS with contributions from OD, RSY, BY, JCWO, FK and BK. IRSS Bobo and IRSS Ouaga: chemical analysis. UPB: academic training of OD under supervision of MTC and GAO. Phytofla laboratory: provide plant materials. The paper was drafted by OD and supervised by JCWO, MTC and GAO. OD, RSY, JBO, MTC and JCWO participated in the overall running of the project. "Saye" and plants samples were provided by ZPD. All the authors have read and approved the final manuscript.

\section{REFERENCES}

Awomukwu DA, Nyananyo BL, Ikpeama AI, Adieze CU. 2015. Comparative chemical constituents of some Cassia species and their pharmacognistic importance in South Eastern Nigeria. Science Journal of Chemistry, 3(3): 40-49. Doi: 10.11648/j.sjc.20150303.12 ISSN: 23300981.

Benoit-Vical F, Valentin A, Mallie M, Bessiere JM. 2001. Antiplasmodial activity of Cochlospermum planchonii and $C$. tinctorium tubercle essential oils. Journal of Essential Oil Research, 13(1): 65-67. DOI: 10.1080/10412905.2001. 9699609

Ciulei I. 1982. Methodology of Analysis of Vegetal Drug. Pratical Manual on Industrial Utilization of Medicinal and Aromatic Plants. Bucharest (Faculty of pharmacy), $67 \mathrm{p}$.

Da O, Traore/Coulibaly M, Yerbanga RS, Koama B, Ouedraogo N, Tamboura S,. Dakuyo ZP, Sekhoacha MP, Nikiema JB, Ouedraogo GA, Matsabisa MG, Ouedraogo JB. 2014. Antiplasmodial and Antioxidant Activities of Saye: A Traditional Herbal Remedy for Malaria. American Journal of Biochemistry and 
Molecular Biology, 4: 155-166. DOI: 10.3923/ajbmb.2014.155.166

Dakuyo Z, Meda AL, Da O, Kiendrebeogo M, Traore-Coulibaly M, Novak J, BenoitVical F, Weisbord E, Willcox M. 2015.: SAYE: The Story of an Antimalarial Phytomedicine from Burkina Faso. $J$ Altern Complement Med., 21:187-195. DOI: $10.1089 / \mathrm{acm} .2014 .0147$

Ezeja MI, Anaga AO. 2010. Anti-diarrhoeal Activities of the Methanolic Root Bark extract of Cochlospermum planchonii (Hook f). International Journal of Toxicological and Pharmacological Research; 2(2): 40-44. http://www.ijtpr.com.

Ginsburg H, Deharo E. 2011. A call for using natural compounds in the development of new antimalarial treatments-an introduction. Malar J., 10(1): S1. DOI: 10.1186/1475-2875-10-S1-S1

Hemant D, Chandewar AV. 2013. A review on pharmacognostical, phytochemical, pharmacological properties of Phyllanthus amaru. International Journal of Biomedical And Advance Research (IJBAR) 281-288. DOI:10.7439/ijbar

Kayembe JS, Taba KM, Ntumba K, Kazadi TK. 2012. In vitro Antimalarial Activity of 11 Terpenes Isolated from Ocimum gratissimum and Cassia alata Leaves. Screening of Their Binding Affinity with Haemin. Journal of Plant Studies, 1(2): 168-172. DOI: $10.5539 / j p s . v 1 n 2 p 168$

Matthew OA, Gambo NN. 2013. Phytochemistry and Antimicrobial Activity of the Leaf of cassia alata LINN. Chemistry and Materials Research, 3(3): 96-101. http://www.iiste.org

Nafiu MO, Akanji MA, Yakubu MT. 2011. Phytochemical and Mineral Constituents of Cochlospermum planchonii (Hook. Ef. x Planch) Root. Bioresearch Bulletin, 5: 51-56. http://bioresonline.com/ Documents/AA000195.pdf

Obianime AW, Uche FI. 2009. The Phytochemical constituents and the effects of methanol extracts of Phyllanthus amarus leaves (kidney stone plant) on the hormonal parameters of Male guinea pigs. J. Appl. Sci. Environ. Manage, 13(1): 5-9. DOI: 10.4314/jasem.v13i1.55250

White NJ. 2004. Antimalarial drug resistance. $J$ Clin Invest., 113(8): 1084-1092. DOI: 10.1172/JCI200421682

World Malaria Report. 2015. World Malaria Report. World Health Organization: Geneva. 